\title{
Effects of temperature on photosynthetic parameters and TEP production in eight species of marine microalgae
}

\author{
Pascal Claquin ${ }^{1, *}$, Ian Probert ${ }^{2}$, Sébastien Lefebvre ${ }^{1}$, Benoît Veron ${ }^{1,3}$ \\ ${ }^{1}$ Laboratoire de Biologie et Biotechnologies Marines UMR M 100 IFREMER-PE2M, Université de Caen Basse-Normandie, \\ Esplanade de la paix, 14032 Caen Cedex, France \\ ${ }^{2}$ CNRS Station Biologique de Roscoff, Place Georges Teissier, 29682 Roscoff Cedex, France \\ ${ }^{3}$ Algobank Caen, Université de Caen Basse-Normandie, Esplanade de la paix, 14032 Caen Cedex, France
}

\begin{abstract}
The effects of temperature on photosynthesis and transparent exopolymeric particle (TEP) production for 8 planktonic species belonging to 3 microalgal phyla (Heteronkontophyta, Dinophyta and Haptophyta) were investigated. Nutrient-replete semicontinuous cultures were grown at 13 temperatures between 5 and $25^{\circ} \mathrm{C}$ or $35^{\circ} \mathrm{C}$ (depending on the lethal temperature). A non-linear parametric model was applied to data on growth rate, photosynthetic parameters (electron transport rate, ETR), light utilization efficiency, $\alpha$ ) and TEP production. The maximal photosynthetic activity at optimal temperature of production varied from 2.70 (Pavlova lutheri) to 4.64 (Thalassiosira pseudonana) mmol $\mathrm{e}^{-}(\mathrm{mg} \text { chl } a)^{-1} \mathrm{~h}^{-1}$. The variation in the photoacclimation state confirmed the similarity of acclimation trends at low temperature to those at high irradiance. However, different responses were observed between species, highlighting the fact that photoacclimation mechanisms vary interspecifically for both light harvesting and downstream photosynthetic metabolism. TEP production was lowest in Isochrysis galbana and greatest in Lepidodinium chlorophorum (6 vs. $380 \mathrm{mg}$ xanthan equiv [mg chl a $]^{-1} \mathrm{~d}^{-1}$ ). The proportion of carbon fixed by photosynthesis and excreted as TEP was $70.8 \%$ for $L$. chlorophorum, while other species excreted 6.7 to $30 \%$. A linear relationship was found between the $\operatorname{ETR}(T)$ and TEP $(T)$ models for the 3 diatoms, indicating a coupling between photosynthetic activity and TEP production. This provides a new outlook on carbon excretion, which has classically been described as a consequence of nutrient stress.
\end{abstract}

KEY WORDS: Transparent exopolymeric particle . Excretion - Electron transport rate - ETR - Diatom . Dinophyta $\cdot$ Haptophyta

\section{Resale or republication not permitted without} written consent of the publisher

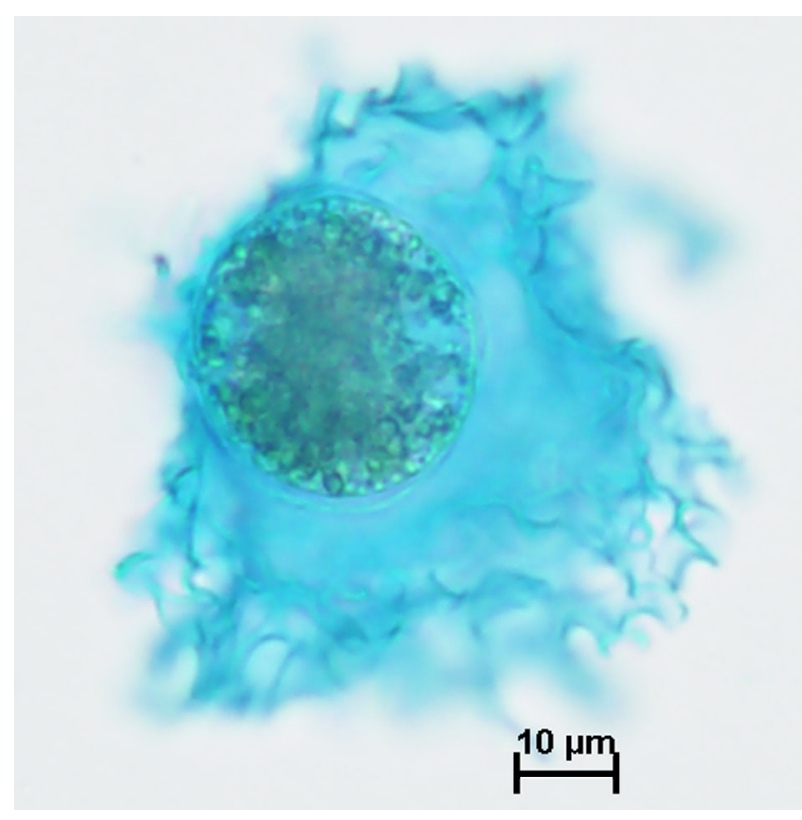

TEP excretions by Lepidodinium chlorophorum stained with alcian blue.

Photo: P. Claquin

\section{INTRODUCTION}

Microalgae and bacteria may excrete large quantities of polysaccharides, which represent a considerable amount of organic carbon (Passow 2002a). The colloidal fraction of these microbially derived dissolved polysaccharides is the main source for the abiotic formation (by coagulation) of transparent exopolymeric particles (TEPs), a type of exopolymeric substance (EPS). TEPs are heavily implicated in biogeochemical 
cycling of carbon and other elements in the marine environment, notably through involvement in aggregation mechanisms which can influence sedimentation of phytoplankton blooms (Thornton 2002). They are also important in ecological contexts since they may affect grazing (Prieto et al. 2001) and may inhibit viral infection (Brussaard et al. 2005).

The products of photosynthesis can be excreted within a few hours of formation (Underwood et al. 2004). Excretion of TEP precursors by microalgae is known to be enhanced under nutrient stress (Staats et al. 2000, Passow 2002b, Underwood et al. 2004), which is often considered to be the consequence of an overflow of photosynthate produced in excess of cellular requirements (Staats et al. 2000). Underwood et al. (2004) described the formation of 2 types of EPS depending on nutrient status; the first type was produced under non-limiting conditions and the second under limitation, revealing different mechanisms implicated in carbon excretion, some of which are not necessarily linked to metabolic overflow processes. Photosynthesis, like all metabolic processes, is affected by temperature (Davison 1991). Microalgae manifest a range of physiological responses to temperature changes (Thompson 2006), but the effect of temperature on carbon excretion has rarely been studied. In non-thermal acclimated cultures of benthic diatoms, Wolfstein \& Stal (2002) observed that carbon excretion relative to biomass was higher at low temperature. Parallel temperaturedependent changes in photosynthesis and dissolved organic carbon (DOC) excretion were observed in batch cultures of the chlorophyte Chlorella vulgaris and the cyanobacterium Synechococcus sp., while DOC excretion was temperature independent in the haptophyte Isochrysis galbana (Zlotnik \& Dubinsky 1989).

In the present study, we evaluated the effects of temperature in nutrient-replete conditions on photosynthetic parameters and on TEP production in 8 species belonging to the dominant marine microalgal groups: diatoms (Bacillariophyceae, Heterokontophyta), dinoflagellates (Dinophyceae, Dinophyta) and haptophytes (Pavlovophyceae and Prymnesiophyceae, Haptophyta). These planktonic species were selected on the basis of their relevance in ecological and biogeochemical contexts and/or for their use as live feed in shellfish aquaculture.

\section{MATERIALS AND METHODS}

Culture conditions. Eight species of microalgaeThalassiosira pseudonana Hasle et Heimdal (Bacillariophyceae, AC589), Skeletonema marinoi Sarno et Zingone (Bacillariophyceae, AC174), Pseudo-nitzschia fraudulenta (Cleve) Hasle (Bacillariophyceae), Emil- iana huxleyi (Lommann) Hay et Mohler morphotype A (Prymnesiophyceae, AC474), Isochrysis galbana Green (Prymnesiophyceae, AC34), Isochrysis aff. galbana (termed T-Iso. Tahitian isolate) (Prymnesiophyceae, AC102), Pavlova lutheri (Droop) Green (Pavlovophyceae, AC44) and Lepidodinium chlorophorum (Elbrächter et Schnepf) Hansen, Botes et de Salas (Dinophyceae, AC195)-obtained from the Algobank-Caen culture collection (University of Caen Basse-Normandie, France) were grown in semicontinuous culture at 13 different temperatures between 5 and $25^{\circ} \mathrm{C}$ or $35^{\circ} \mathrm{C}$ (depending on the lethal temperature). The cultures of T. pseudonana, S. marinoi and $P$. lutheri were axenic. The other cultures were not completely axenic, but the level of bacterial contamination was controlled and was extremely low. Cultures $(50 \mathrm{ml})$ were grown in $150 \mathrm{ml}$ borosilicate Erlenmeyer flasks in sterile natural seawater (salinity 35 ) enriched with $f / 2$-medium supplements. The temperature gradient was obtained using a $2 \mathrm{~cm}$ thick, $1.5 \times 0.6 \mathrm{~m}$ aluminium plate with a $1 \mathrm{~cm}$ diameter ( $0.6 \mathrm{~m}$ long) hole drilled $2 \mathrm{~cm}$ from each end, through which distilled water was pumped. Water passing through the hole at either side of the plate was circulated through a separate closed system water bath and the temperature gradient across the plate was regulated by controlling the temperature in each water bath. Cultures were acclimated for at least $1 \mathrm{wk}$ at each temperature. The cultures were illuminated continuously at an intensity of $130 \mu \mathrm{mol}$ photons $\mathrm{m}^{-2} \mathrm{~s}^{-1}$ provided by daylight fluorescent lamps. Light intensity was measured in the culture using a micro-spherical quantum sensor (US-SQS/L Walz). Cultures were manually mixed by gentle swirling 3 times per day. In order to maintain the cultures in exponential phase at a constant growth rate without nutrient limitation, they were diluted daily with $f / 2$-medium as described in MacIntyre \& Cullen (2005). After daily dilution, in vivo chlorophyll a (chl a) concentrations were equivalent in all cultures for all temperature conditions, thus minimising light variation between cultures. Biomass was estimated daily before and after dilution by fluorimetric measurement (Turner Designs) of in vivo chl a. Specific growth rates $\left(\mu, \mathrm{d}^{-1}\right)$ were calculated using:

$$
\mu=\ln \left(\operatorname{chl} a_{t} / \operatorname{chl} a_{t_{0}}\right) /\left(t-t_{0}\right)
$$

where $t$ is time in days, chl $a_{t_{0}}$ is initial chl $a$ after dilution (i.e. at the initial time $t_{0}$ ), and chl $a_{t}$ is chl $a$ at time $t$ before the dilution.

The cultures were assumed to be in steady state when daily growth rate and photosynthetic capacity $\left(E R_{\max }\right)$ had been stable for at least $5 \mathrm{~d}$. Triplicate samples were taken on 3 consecutive days once steady state had been attained in each semi-continuous culture. 
Photosynthetic parameters. Chl a was measured spectrophotometrically after extraction in $90 \%$ acetone, and in vivo absorption was measured spectrophotometrically according to Shibata et al. (1954). Chlorophyllspecific absorption cross sections $\left(a^{*} ; \mathrm{m}^{2}[\mathrm{mg} \mathrm{chl}]^{-1}\right)$ were calculated from the chlorophyll concentration and in vivo absorption (Dubinsky et al. 1986).

ETR $_{\text {max }}$ was quantified by measuring variable fluorescence. The maximum energy conversion efficiency, or quantum efficiency of PSII charge separation $\left(F_{\mathrm{v}} / F_{\mathrm{m}}\right)$, was measured using a WATER/B PAM (Walz) (Schreiber et al. 1986). After a dark adaptation period of $15 \mathrm{~min}$ at growth temperature, a $2 \mathrm{ml}$ sub-sample was placed in a darkened measuring chamber. The sample was excited by a weak blue light $\left(1 \mu \mathrm{mol} \mathrm{m} \mathrm{m}^{-2}\right.$ $\mathrm{s}^{-1}, 470 \mathrm{~nm}$, frequency $0.6 \mathrm{kHz}$ ) and fluorescence was detected at wavelengths above $695 \mathrm{~nm} . F_{\mathrm{v}} / F_{\mathrm{m}}$ was calculated by (Genty et al. 1989):

$$
F_{\mathrm{v}} / F_{\mathrm{m}}=\left(F_{\mathrm{m}}-F_{0}\right) / F_{\mathrm{m}}
$$

where $F_{0}$ and $F_{\mathrm{m}}$ are the minimum and maximum fluorescence of a dark-adapted sample during a saturating light pulse $\left(0.6 \mathrm{~s}, 470 \mathrm{~nm}, 1700 \mu \mathrm{mol} \mathrm{m} \mathrm{m}^{-2} \mathrm{~s}^{-1}\right)$, respectively.

A succession of rapid light curves relating the ETR to the irradiance $(E)$ was performed. The samples were exposed to 9 different irradiances from 0 to $1000 \mu \mathrm{mol}$ photon $\mathrm{m}^{-2} \mathrm{~s}^{-1}$ for $40 \mathrm{~s}$ each. The steady-state fluorescence $\left(F_{\mathrm{s}}\right)$ and the maximal fluorescence $\left(F_{\mathrm{m}}{ }^{\prime}\right)$ were measured. According to Genty et al. (1989), the effective quantum efficiency of PSII in actinic irradiance was calculated as:

$$
\Delta F / F_{\mathrm{m}}{ }^{\prime}=\left(F_{\mathrm{m}}{ }^{\prime}-F_{\mathrm{s}}\right) / F_{\mathrm{m}}{ }^{\prime}
$$

$\Delta F / F_{\mathrm{m}}{ }^{\prime}$ can be used to calculate the linear rate of photosynthetic electron transport (ETR) of a single active PSII unit (Genty et al. 1989):

$$
\mathrm{ETR}=\Delta F / F_{\mathrm{m}}{ }^{\prime} \times E \times a^{*} \text { PSII }
$$

where $a^{*}{ }_{\text {PSII }}$ is the optical cross section of PSII. As we could not measure $a^{*}$ PSII, we calculated ETR per unit chlorophyll assuming that $50 \%$ of the absorbed photons are allocated to photoreactions in the PSII (Gilbert et al. 2000). ETR (mmol e- $\left[\mathrm{mg} \mathrm{chl} \mathrm{a}^{-1} \mathrm{~h}^{-1}\right.$ ) was calculated as:

$$
\mathrm{ETR}=\Delta F / F_{\mathrm{m}}{ }^{\prime} \times E \times a^{*} \times 0.5
$$

where $a^{*}$ is the chlorophyll-specific absorption cross section $\left(\mathrm{m}^{2}[\mathrm{mg} \mathrm{chl} \mathrm{a}]^{-1}\right)$. As no significant photo-inhibition was observed, the Webb et al. (1974) model was applied to the data, ETR $_{\max }$ (maximum electron transport rate expressed in mmol $\mathrm{e}^{-}[\mathrm{mg} \mathrm{chl} \mathrm{a}]^{-1} \mathrm{~h}^{-1}$ ) and the initial slope of the ETR $(E)$ curve, or maximal light utilization efficiency $(\alpha)$ in mmol $\mathrm{e}^{-}(\mathrm{mg} \operatorname{chl} a)^{-1} \mathrm{~h}^{-1}(\mu \mathrm{mol}$ photons $\left.\mathrm{m}^{-2} \mathrm{~s}^{-1}\right)^{-1}$, was then calculated as:

$$
\mathrm{ETR}=\mathrm{ETR}_{\max }\left(1-\mathrm{e}^{\left(-\alpha E / E T R_{\max }\right)}\right)
$$

The light saturation parameter $E_{\mathrm{k}}$ was calculated using:

$$
E_{\mathrm{k}}=\mathrm{ETR}_{\max } / \alpha
$$

Colorimetric determination of TEP. The method of Passow \& Alldredge (1995) for determination of TEP concentration and its expression in xanthan equivalents per litre (Xeq $\mathrm{l}^{-1}$ ) was adapted to incorporate the centrifugation protocol (instead of filtration) of Arruda Fatibello et al. (2004). Five ml of culture were centrifuged at $4000 \mathrm{rpm}(3200 \times \mathrm{g})$ for $20 \mathrm{~min}$. Two $\mathrm{ml}$ of $0.02 \%$ Alcian blue (Sigma) in $0.06 \%$ acetic acid prepared as described in Passow \& Alldredge (1995) was added to the pellet. The sample was centrifuged $(3200 \times g, 20 \mathrm{~min})$ immediately in order to remove the excess dye. The pellet was rinsed with $1 \mathrm{ml}$ of distilled water and centrifuged several times until excess dye was totally removed. Four $\mathrm{ml}$ of $80 \% \mathrm{H}_{2} \mathrm{SO}_{4}$ were then added to the pellet. After $2 \mathrm{~h}$, the absorption of the supernatant was measured at $787 \mathrm{~nm}$. No precipitation of Alcian blue due to salt residue was observed in blanks. The calibration standard preparation described in Passow \& Alldredge (1995) is applicable only for very low concentrations of TEP, i.e. calibration standard weight of xanthan gum ranging between 0 and $40 \mu \mathrm{g}$, which was not suitable for our samples. Moreover, these authors reported that only $16 \%$ of aqueous xanthan gum standard solution was retained on filters. In addition, the absorption of the blank obtained by Passow \& Alldredge (1995) was always quite high. A protocol based on that of Passow \& Alldredge (1995) but adapted to our experimental needs was consequently developed. A standard suspension of $1.0 \mathrm{~g} \mathrm{l}^{-1}$ of xanthan gum in absolute ethanol was prepared. This standard suspension was mixed for $20 \mathrm{~min}$ and then sonicated in order to obtain small particles. Between $10 \mu \mathrm{l}$ and $0.8 \mathrm{ml}$ of this suspension was mixed with $2 \mathrm{ml}$ of the solution of Alcian blue and then centrifuged at $3200 \times$ $g$ for $30 \mathrm{~min}$. The pellet obtained was carefully rinsed with ethanol until the supernatant was clear (at least 3 times). The ethanol was then evaporated at $30^{\circ} \mathrm{C}$ overnight. Since xanthan gum does not dissolve in ethanol, the amount of xanthan gum in the dry residue was known. By weighing dried xanthan gum before and after treatment procedures, overall loss of xanthan during the treatment were estimated to be lower than $5 \%$. Six $\mathrm{ml}$ of $80 \% \mathrm{H}_{2} \mathrm{SO}_{4}$ were then added to the pellet and absorption was measured as described above. The standard curve was highly reproducible over a large range of concentrations (Fig. 1). The protocol was validated on several microalgal strains and each time a linear relationship 


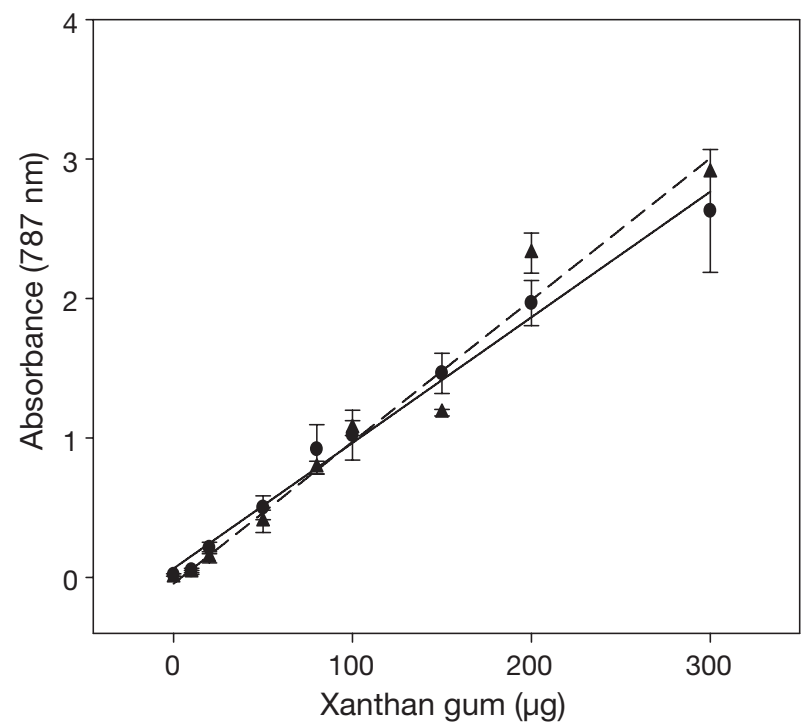

Fig. 1. Two standard curves made with xanthan gum coloured with Alcian blue after sulphuric acid treatment. Values of absorbance were corrected for blanks (the absorbance of blanks was <0.02). Linear regressions were fitted to experimental data: dashed line, $y=0.010 x-0.043\left(\mathrm{r}^{2}=0.97\right)$; solid line, $y=0.009 x-0.065\left(r^{2}=0.99\right) ;$ Means \pm SD $(n=3)$ are shown

was found between microalgal biomass (chlorophyll or cell number) and TEP concentration. Some examples are shown in Fig. 2.

TEP production (mg Xeq $[\mathrm{mg} \mathrm{chl} \mathrm{a}]^{-1} \mathrm{~d}^{-1}$ ) was estimated in steady state by measuring the TEP concentration per chl a unit (mg Xeq $[\mathrm{mg} \mathrm{chl} \mathrm{a}]^{-1}$ ) before the daily dilution. Knowing the daily dilution rate $(D)$ expressed in $\mathrm{d}^{-1}$, it was possible to calculate the daily TEP production.

Temperature model. The non-linear parametric model of Blanchard et al. (1996) inspired from O'Neill (Straskraba \& Gnauck 1985) was fitted on growth rates $\left(\mu, \mathrm{d}^{-1}\right), \operatorname{ETR}_{\max }\left(\mathrm{mmol} \mathrm{e}^{-}[\mathrm{mg} \mathrm{chl} a]^{-1} \mathrm{~h}^{-1}\right)$ and TEP production (mg Xeq [mg chl a $]^{-1} \mathrm{~h}^{-1}$ ) as a function of temperature $\left(T,{ }^{\circ} \mathrm{C}\right)$ :

$$
X(T)=X_{\mathrm{MAX}}\left[\frac{\left(T_{\text {let }}-T\right)}{\left(T_{\text {let }}-T_{\text {opt }}\right)}\right]^{\beta} \times \exp \left(-\beta\left\{\left[\frac{\left(T_{\text {let }}-T\right)}{\left(T_{\text {let }}-T_{\text {opt }}\right)}\right]-1\right\}\right)
$$

where $X(T)$ corresponds to $\mu(T), \operatorname{ETR}_{\max }(T), \alpha(T)$ or TEP production( $T) . X_{\text {MAX }}$ represents $\mu_{\text {MAX }}$, ETR $_{\text {MAX, }}$ $\alpha_{\text {MAX }}$ or the maximal TEP production at the optimal temperature $\left(T_{\text {opt }}\right) . T_{\text {let }}$ is the lethal temperature and the shape parameter $\beta$ is a dimensionless parameter related to the $Q_{10}$. To simplify curve fitting, Morris \& Kromkamp (2003) fixed $\beta$ at 1.3. We did not fix $\beta$, but we fixed $T_{\text {let }}$ as a function of experimental data.

$E_{\mathrm{k}}$ being calculated as the ratio of $\mathrm{ETR}_{\max }$ and $\alpha$, the $E / E_{\mathrm{k}}$ model was estimated using the $\operatorname{ETR}_{\max }(T)$ and $\alpha(T)$ models.
All curve fitting was carried out using the least squares criterion of SigmaPlot 10 (Systat Software). All fittings were tested using analyses of variance ( $p<$ 0.001), residuals being tested for normality and homogeneity of variance, and parameter significance by the Student's $t$-test $(\mathrm{p}<0.05)$. In order to evaluate the relationship between $\operatorname{ETR}_{\max }(T)$ and $\operatorname{TEP}(T)$, the shapes of the models were compared using the method of Ratkowski (1983) for non-linear models ( $<$ 0.05), after normalization of the observations by their respective maximum values.

\section{RESULTS}

\section{Growth and photosynthesis as a function of temperature}

The growth rate of the 8 species varied as a function of temperature following the Blanchard et al. (1996) model, which allowed us to determine growth parameters of all of the species (Table 1). The fits of the model were always significant, indicating that growth of the cultures was controlled, as expected, by temperature. Isochrysis galbana presented the minimal value of $\mu_{\max }\left(0.60 \mathrm{~d}^{-1}\right)$ and Thalassiosira pseudonana the maximal value $\left(1.36 \mathrm{~d}^{-1}\right)$. The lowest optimal temperature for growth $\left(T_{\mathrm{opt}(\mu)}\right)$ was recorded for Pseudo-nitzschia

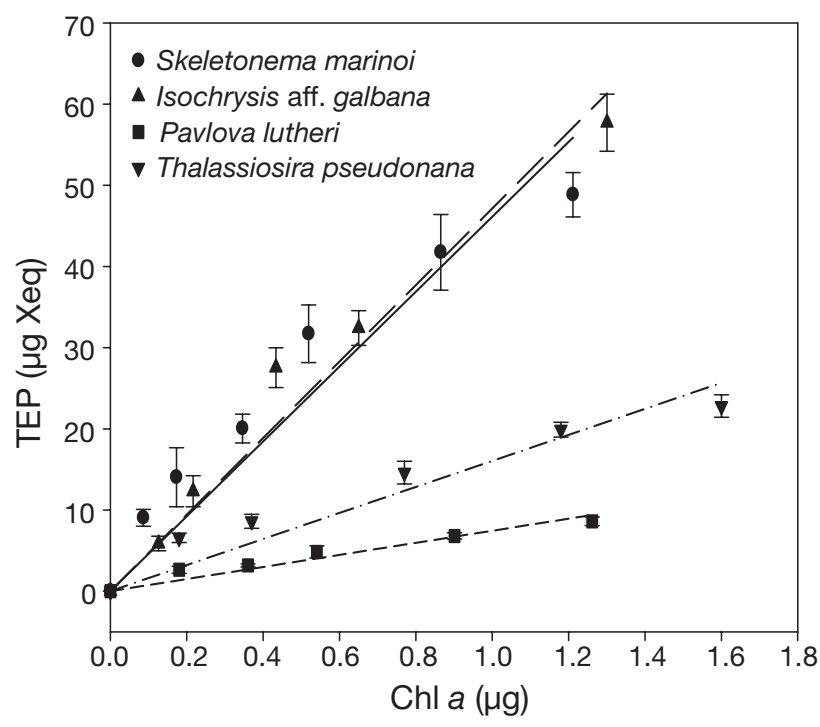

Fig. 2. Example of linear relationships found between microalgal biomass $(\mu \mathrm{g} \mathrm{chl} \mathrm{a)} \mathrm{of} \mathrm{Skeletonema} \mathrm{marinoi}(y=$ $\left.46.13 x, \mathrm{r}^{2}=0.90\right)$, Isochrysis aff. galbana $\left(y=47.13 x, \mathrm{r}^{2}=0.97\right)$, Pavlova lutheri $\left(y=7.43 x, r^{2}=0.93\right)$, Thalassiosira pseudonana $\left(y=16.03 x, r^{2}=0.90\right)$ and transparent exopolymeric particles (TEP; $\mu \mathrm{g}$ Xeq: xanthan equivalents) for validation of our TEP labelling protocol. Means \pm SD $(n=3)$ are shown 


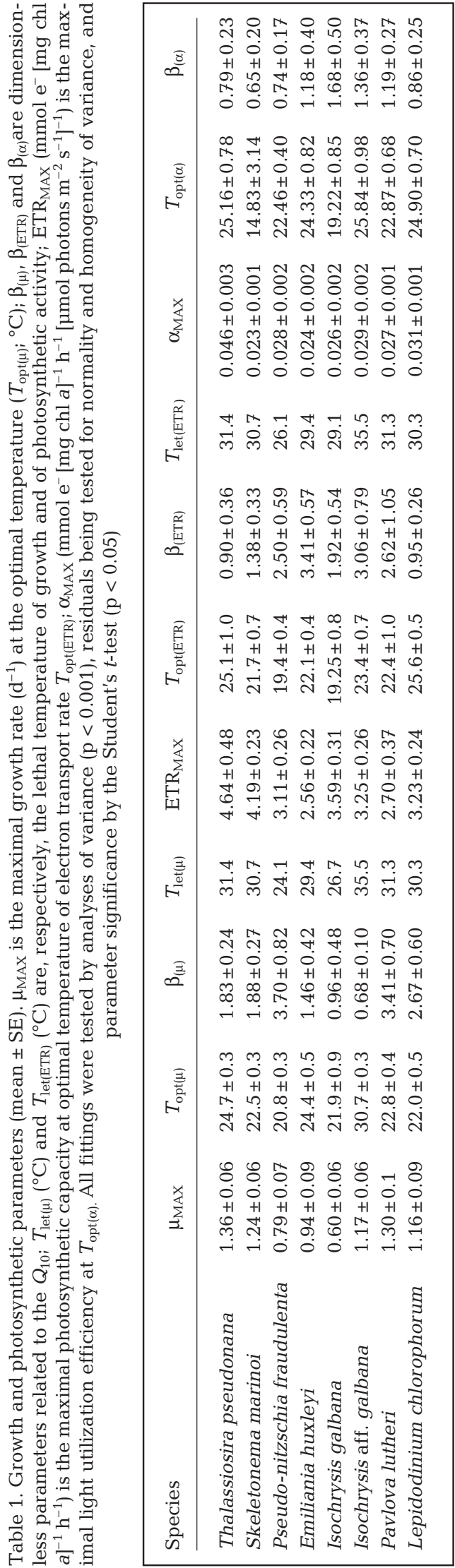

fraudulenta, $20.8^{\circ} \mathrm{C}$, and the highest, $30.7^{\circ} \mathrm{C}$, for $I$. aff. galbana. The $T_{\text {opt }(\mu)}$ of the other tested species were within the range 22.0 to $24.7^{\circ} \mathrm{C}$. P. fraudulenta also presented the lowest lethal temperature $\left(24.1^{\circ} \mathrm{C}\right)$, and $I$. aff. galbana the highest $\left(35.5^{\circ} \mathrm{C}\right)$. The $\mathrm{ETR}_{\max }$ was determined at each temperature (Fig. 3). For the 8 species, the data obtained fitted significantly with the tempera-

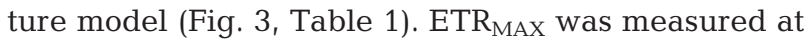
the optimal temperature of production $\left(T_{\mathrm{opt}(\mathrm{ETR})}\right)$ and varied from $2.70 \mathrm{mmol} \mathrm{e}^{-}(\mathrm{mg} \mathrm{chl} \mathrm{a})^{-1} \mathrm{~h}^{-1}$ for Pavlova lutheri to $4.64 \mathrm{mmol} \mathrm{e}^{-}(\mathrm{mg} \mathrm{chl} \mathrm{a})^{-1} \mathrm{~h}^{-1}$ for T. pseudonana. $T_{\mathrm{opt}(\mu)}$ and $T_{\mathrm{opt}(\mathrm{ETR})}$ were not significantly different for T. pseudonana, Skeletonema marinoi, $P$. fraudulenta and $P$. lutheri $(\mathrm{p}>0.05)$, while they were significantly different for the other 4 species $(p<0.05)$. No significant variations of $a^{*}$ were found as a function of tem-
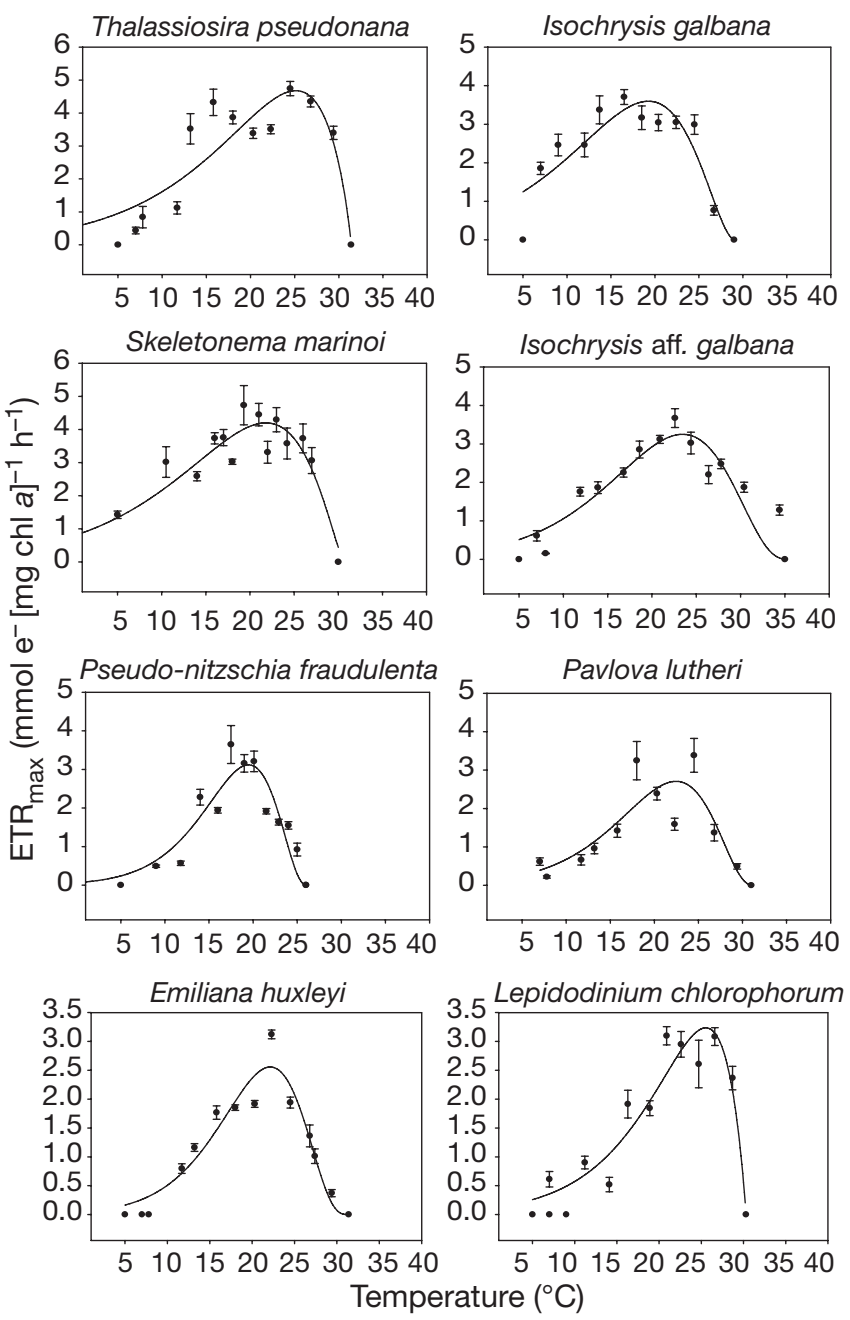

Fig. 3. Photosynthetic capacities $\left(\mathrm{ETR}_{\max }\right)$ of 8 phytoplankton species grown in semi-continuous culture as a function of temperature. Means \pm SE of triplicate cultures are shown; fitted lines represent the Blanchard et al. (1996) model $\operatorname{ETR}_{\max }(T)$ 
perature for all species. The average values of $a^{*}$ (expressed in $\mathrm{m}^{2} \mathrm{chl} \mathrm{a}^{-1}$ ) were $2.69 \times 10^{-2}$ for T. pseudonana, $2.62 \times 10^{-2}$ for $S$. marinoi, $2.79 \times 10^{-2}$ for $P$. fraudulenta, $2.80 \times 10^{-2}$ for Emiliania huxleyi, $2.62 \times 10^{-2}$ for $I$. galbana, $2.26 \times 10^{-2}$ for $I$. aff. galbana, $2.25 \times 10^{-2}$ for $P$. lutheri and $3.32 \times 10^{-2}$ for Lepidodinium chlorophorum. The chlorophyll content per cell tended to increase with rising temperature (data not shown) as classically described in the literature (Berges et al. 2002).

In contrast to $\mu$ and $\mathrm{ETR}_{\max }$, which followed the same trend for all species (i.e. O'Neill bell shape model), $\alpha$ did not present the same trend as a function of temperature for the 8 species (Fig. 4). The classic bell shape of the model fitted significantly with the observations for Thalassiosira pseudonana, Emiliania huxleyi, Pavlova lutheri, Isochrysis aff. galbana, I. galbana and Lepido- dinium chlorophorum, $\alpha$ increasing with temperature, reaching a steady state before $T_{\mathrm{opt}(\mathrm{ETR})}$ and starting to decrease at high temperature up to the lethal temperature. For the 2 other species, the model also fitted significantly; however, for Pseudo-nitzschia fraudulenta, $\alpha$ increased continuously with temperature up to $T_{\text {let }}$ and stayed relatively constant around $3.2 \times 10^{-3}$ mmol e $\mathrm{e}^{-}(\mathrm{mg} \mathrm{chl} \mathrm{a})^{-1} \mathrm{~h}^{-1}$ ( $\mu \mathrm{mol}$ photons $\left.\mathrm{m}^{-2} \mathrm{~s}^{-1}\right)^{-1}$ over the temperature range for Skeletonema marinoi.

The parameter $E / E_{\mathrm{k}}$ (corresponding to the ratio between the experimental growth irradiance and the light-saturation parameter, $E_{\mathrm{k}}$ ) showed various patterns as a function of species, as shown by the $E / E_{\mathrm{k}}$ model (Fig. 5). For Thalassiosira pseudonana and Isochrysis galbana the $E / E_{\mathrm{k}}$ ratio was quite stable. For Skeletonema marinoi and Lepidodinium chloropho-

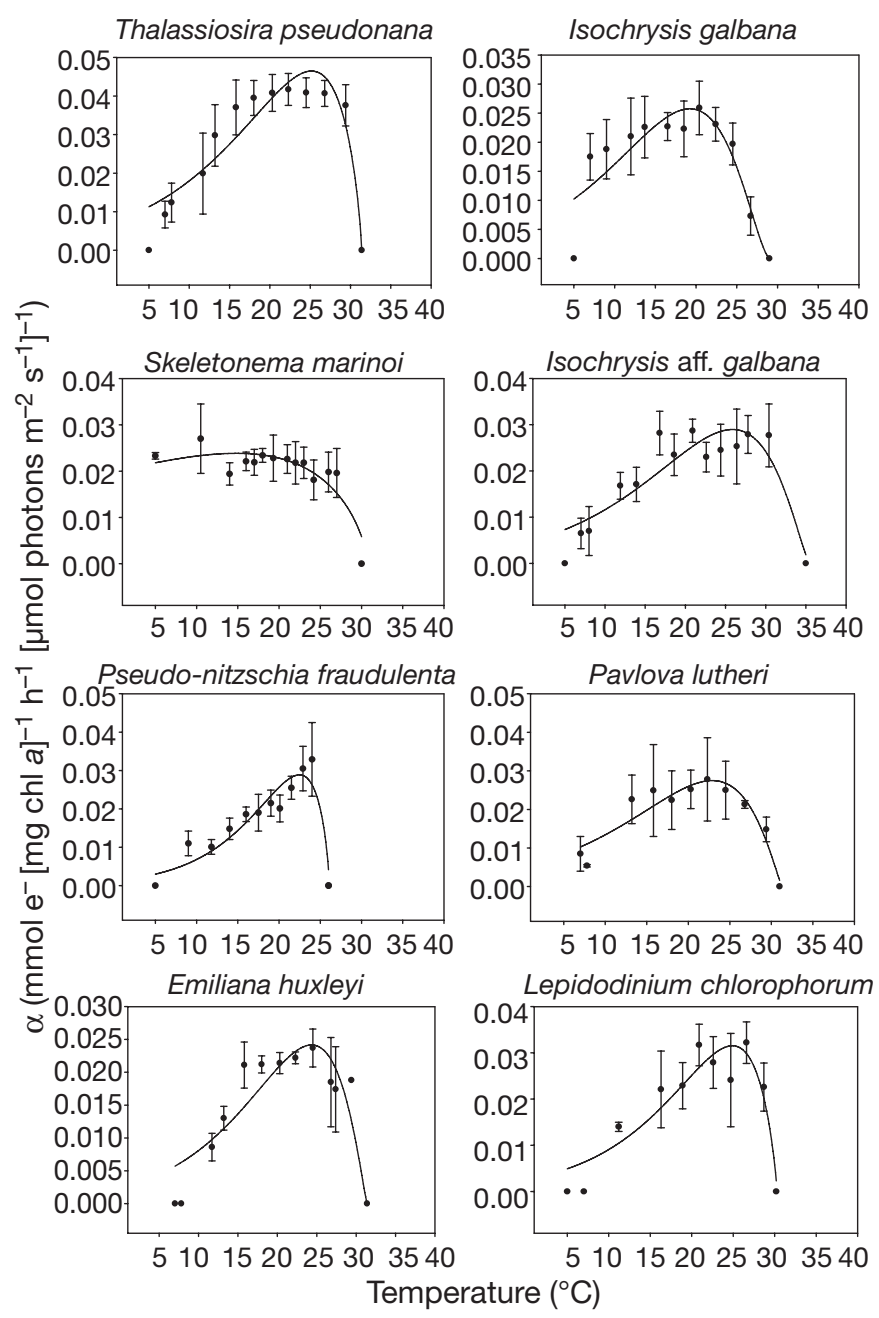

Fig. 4. Photosynthetic efficiency $(\alpha)$ of 8 phytoplankton species grown in semi-continuous culture as a function of temperature. Means \pm SE of triplicate cultures are shown; fitted lines represent the Blanchard et al. (1996) model $\alpha(T)$

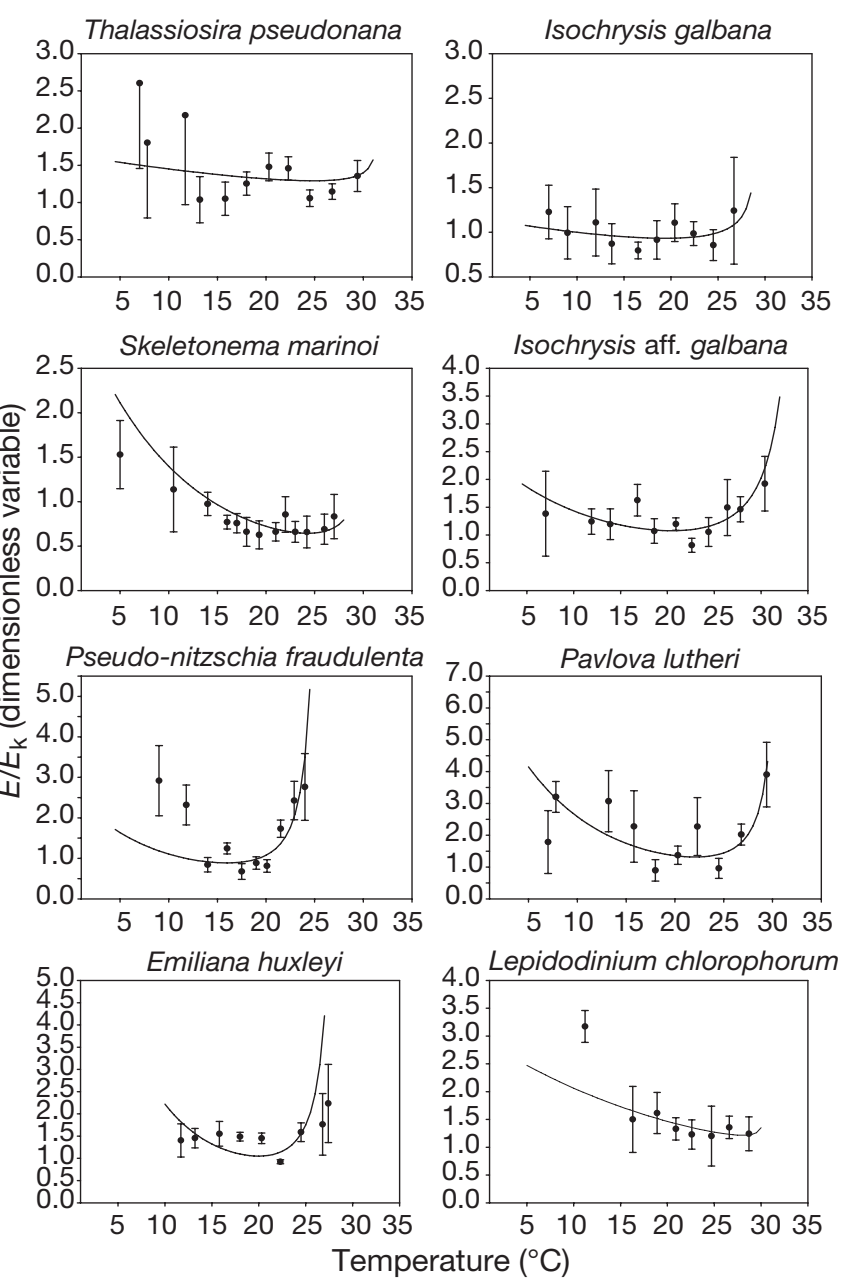

Fig. 5. Ratio of irradiance of growth $(E)$ to the light saturation parameter $\left(E_{\mathrm{k}}\right)$ for 8 phytoplankton species grown in semicontinuous culture as a function of temperature. Means $\pm \mathrm{SE}$ of triplicate cultures are shown; fitted lines represent the evolution of the $E / E_{\mathrm{k}}$ model estimated using the $\operatorname{ETR}_{\max }(T)$ and $\alpha(T)$ models 
rum, the ratio was relatively high at low temperature. For the 4 other species, the $E / E_{\mathrm{k}}$ ratio increased at both low and high temperatures, e.g. the $E / E_{\mathrm{k}}$ ratio of Pseudo-nitzschia fraudulenta rose above $20^{\circ} \mathrm{C}$ and reached 2.7 at $24^{\circ} \mathrm{C}$.

\section{TEP production as a function of temperature}

TEP production per chl a unit varied as a function of temperature and the model fitted significantly with the observations for Thalassiosira pseudonana, Pseudonitzschia fraudulenta, Skeletonema marinoi, Isochrysis galbana and I. aff. galbana (Fig. 6). For these species, the production of TEP increased with temperature until a maximum and decreased at high temperature.
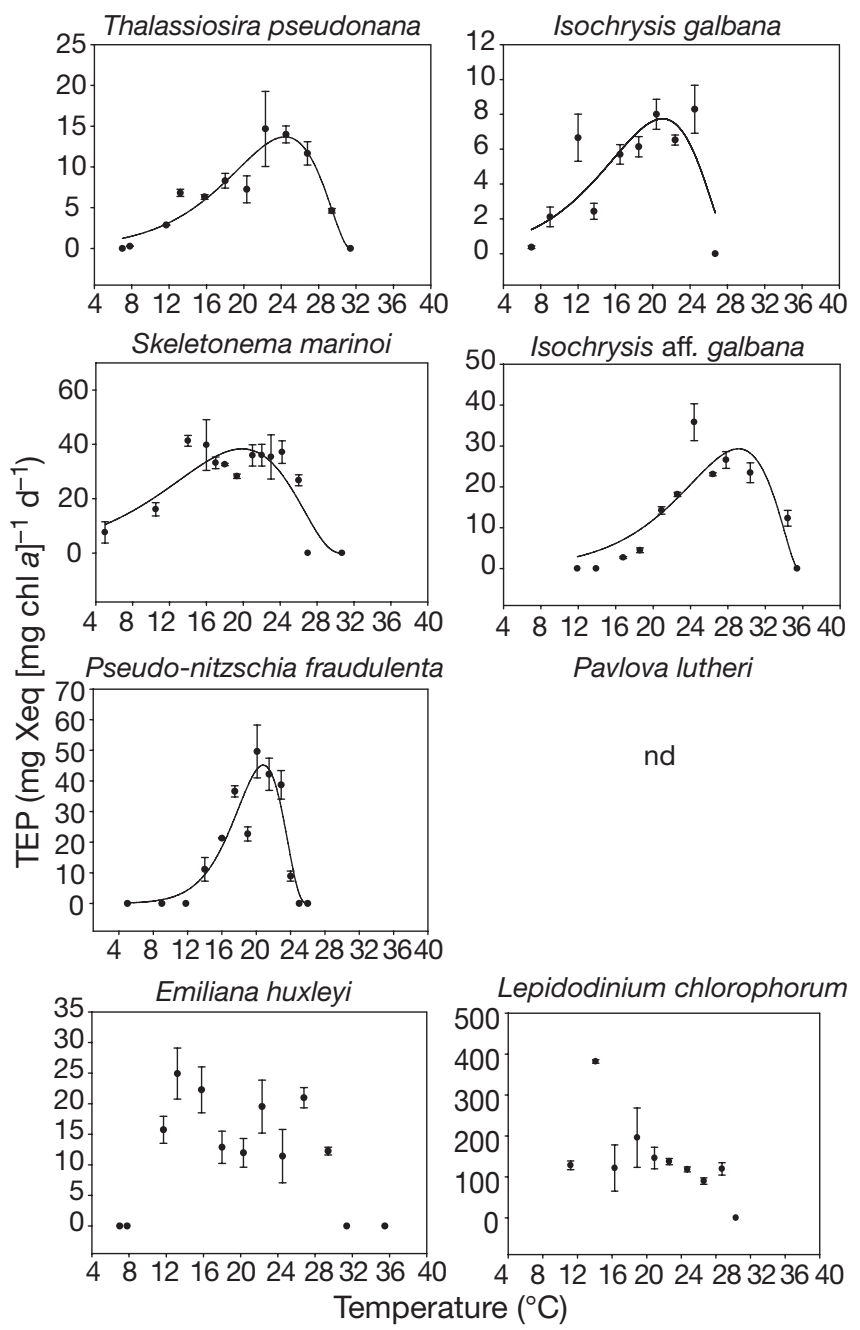

Fig. 6. Transparent exopolymeric particle (TEP) production of 8 phytoplankton species grown in semi-continuous culture as a function of temperature. Means $\pm \mathrm{SE}$ of triplicate cultures are shown; fitted lines represent the Blanchard et al. (1996) model TEP $(T)$. nd: not determined
The same trend was observed for Lepidodinium chlorophorum, but the model did not fit significantly with the data. For Emiliania huxleyi no relationship appeared between temperature and TEP production. The dinoflagellate $L$. chlorophorum produced a large amount (on average 10 times more) of TEP in comparison with the other tested species. The maximum production measured for this species was $380 \mathrm{mg}$ Xeq (mg chl a) $)^{-1} \mathrm{~d}^{-1}$. The diatoms $P$. fraudulenta and $S$. marinoi produced up to ca. $40 \mathrm{mg}$ Xeq $(\mathrm{mg} \mathrm{chl} \mathrm{a})^{-1} \mathrm{~d}^{-1}$. I. aff. galbana produced 4 times more TEP than I. galbana, which produced only $6 \mathrm{mg}$ Xeq $(\mathrm{mg} \mathrm{chl} \mathrm{a})^{-1} \mathrm{~d}^{-1}$. E. huxleyi produced up to $25 \mathrm{mg}$ Xeq $(\mathrm{mg} \mathrm{chl} \mathrm{a})^{-1} \mathrm{~d}^{-1}$ and $T$. pseudonana $15 \mathrm{mg}$ Xeq (mg chl a) ${ }^{-1} \mathrm{~d}^{-1}$.

\section{Relationship between photosynthesis and TEP production}

Using the method of Ratkowski (1983), no differences were found in the shape of the normalized models between $\operatorname{ETR}_{\max }(T)$ and $\operatorname{TEP}(T)$ for Skeletonema marinoi and Pseudo-nitzschia fraudulenta (comparison for non-linear models, $\mathrm{p}>0.05)$. This means that $T_{\mathrm{opt}}$ and $\beta$ (dimensionless parameter related to $Q_{10}$ ) were similar for the 2 models. A difference was found for Thalassiosira pseudonana between the 2 models due to $\beta$ ( $\mathrm{p}<0.05)$, while $T_{\text {opt }}$ was not different. For all other species the comparison between the 2 normalized models was not significant. For the 3 diatoms, linear regressions were found between the 2 models ( $p<$ $0.01), \operatorname{ETR}(T)$ at growth irradiance and $\operatorname{TEP}(T)$, the coefficients of determination, $\mathrm{r}^{2}$, being respectively 0.94, 0.91 and 0.84 for T. pseudonana, S. marinoi and P. fraudulenta (Fig. 7).

\section{DISCUSSION}

In culture, the 8 tested microalgal strains were able to survive over a large temperature range, all growing at least between 7 and $24^{\circ} \mathrm{C}$ (Fig. 3). Consequently, they can be characterized as temperate eurythermal organisms, in contrast to stenothermal microalgae like, for example, Antarctic or Arctic diatoms (Suzuki \& Takahashi 1995), some of which showed maximum growth at $0^{\circ} \mathrm{C}$ and full inhibition of cell division above $7^{\circ} \mathrm{C}$ (Longhi et al. 2003). The haptophyte Isochrysis aff. galbana exhibited the largest range of thermal tolerance, between 7 and $35.5^{\circ} \mathrm{C}$, while the diatom Pseudonitzschia fraudulenta had the lowest range (5 to $\left.24.1^{\circ} \mathrm{C}\right)$.

Relative ETR is frequently used to characterize $\mathrm{ETR}_{\text {max }}$ in algae under various growth conditions (Ralph \& Gademann 2005). Knowing the $a^{*}$, the ETR 


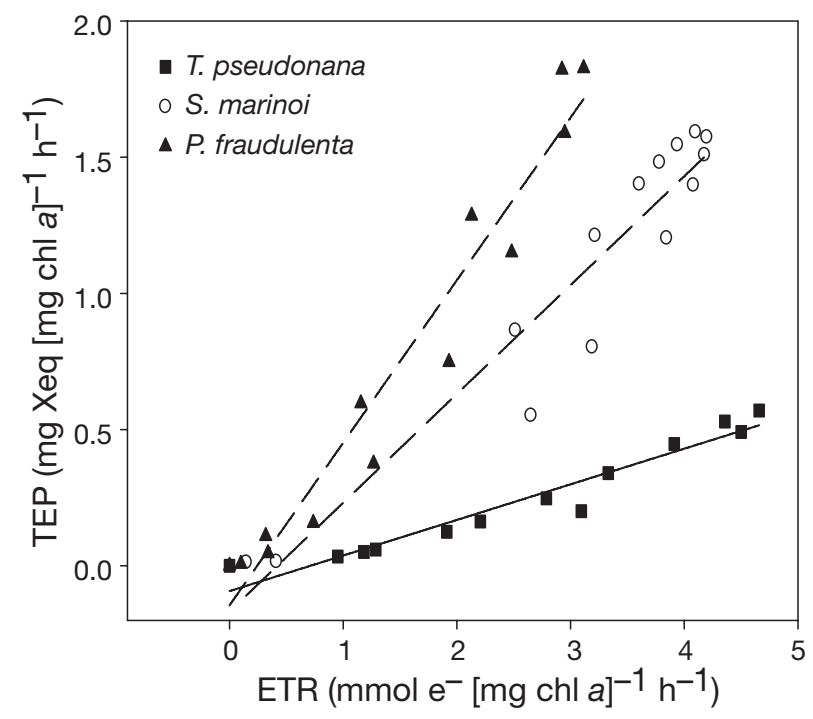

Fig. 7. Linear regression between both models, ETR $(T)$ at growth irradiance (i.e. photosynthetic activity) and TEP $(T)$ for the diatoms Thalassiosira pseudonana $\left(y=0.13 x-0.09, r^{2}=\right.$ 0.94, $\mathrm{p}<0.01)$, Skeletonema marinoi $\left(y=0.40 x-0.16, \mathrm{r}^{2}=\right.$ $0.91, \mathrm{p}<0.01)$ and Pseudo-nitzschia fraudulenta $(y=0.59 x-$ $\left.0.14, \mathrm{r}^{2}=0.95, \mathrm{p}<0.01\right) ; \operatorname{ETR}(T)$ : model of photosynthetic activity as a function of temperature; TEP $(T)$ : model of TEP production as a function of temperature, expressed in $\mathrm{mg}$ Xeq (mg chl a $)^{-1} \mathrm{~h}^{-1}$ for reconciling the time unit; Symbols: estimated values of TEP production as a function of ETR at experimental growth temperatures

was expressed in the present study as a function of chl a concentration, which allows comparison of the photosynthetic parameters of tested species (Fig. 3). The values of ETR $\mathrm{max}_{\text {and }} \alpha$ were within the range of values reported in the literature (Morris \& Kromkamp 2003, Lefebvre et al. 2007). For example, ETR $\max$ varied between 2.3 and $7.1 \mathrm{mmol} \mathrm{e}^{-}(\mathrm{mg} \mathrm{chl} \mathrm{a})^{-1} \mathrm{~h}^{-1}$ in the diatom Skeletonema marinoi in this study and between 1.3 and $7.2 \mathrm{mmol} \mathrm{e}^{-}(\mathrm{mg} \mathrm{chl} \mathrm{a})^{-1} \mathrm{~h}^{-1}$ in another diatom, Cylindrotheca closterium (Morris \& Kromkamp 2003). The 2 centric diatoms, Thalassiosira pseudonana and S. marinoi, presented the highest $\mu_{\mathrm{MAX}}$ and ETR $_{\mathrm{MAX}}$ (Table 1). The relative efficiency with which diatoms are able to transform photosynthetic energy to growth, due in part to the low loss of photosynthetic electrons to alternative pathways like photorespiration and the Mehler-reaction (Wilhelm et al. 2006), can probably partly explain the ecological success of this microalgal group in modern oceans.

Contrary to $\mathrm{ETR}_{\max }$ (Fig. 3), which showed a common pattern of variation as a function of temperature, thermal acclimation of $\alpha$ appeared to be species dependent (Fig. 4). In particular, unlike for other species, $\alpha$ was quite stable with temperature for $S$. marinoi. Stability of $\alpha_{\text {(ETR) }}$ was also observed by Lefebvre et al. (2007) in $S$. costatum (=S. marinoi according to Sarno et al.
2005) and by Morris \& Kromkamp (2003) in C. closterium at high growth rate. Contrary to the other species, $S$. marinoi was able to photosynthesise and grow under $5^{\circ} \mathrm{C}$, indicating that it did not reach its minimal threshold temperature, which probably explains the high value of $\alpha$ at $5^{\circ} \mathrm{C}$. This capacity may account for the wide geographic distribution of Skeletonema spp. (Suzuki \& Takahashi 1995). $\alpha$ is known to be modulated as a function of irradiance and light spectrum (Sakshaug et al. 1997). Our experiments were performed at constant light (in quantity and in spectrum) in semi-continuous culture, which allowed maintenance of a stable level of biomass. Therefore, $\alpha$ variation cannot be explained by an auto-shading effect. The reduction of $\alpha$ observed in many species at low temperature (Fig. 4) was probably partly due to the decreased chlorophyll content per cell recorded with decreasing temperature (data not shown). A decrease in chlorophyll content is a typical algal response to high irradiance, along with increased content of photoprotective carotenoids whose function is to dissipate excess energy. Several previous studies have shown that acclimation to low temperature mimics adaptation to high irradiance (Anning et al. 2001, El-Sabaawi \& Harrison 2006).

The $E / E_{\mathrm{k}}$ models applied on data allowed definition of statistically significant trends upon which the following interpretation is based. The $E / E_{\mathrm{k}}$ ratio was close to 1 around the optimal temperature for all species and the value was higher than 1 both below and above those optimal temperatures notably for the haptophytes Emiliania huxleyi, Isochrysis aff. galbana, Pavlova lutheri and the diatom Pseudo-nitzschia fraudulenta (Fig. 5). For Lepidodinium chlorophorum and Skeletonema marinoi, the $E / E_{\mathrm{k}}$ ratio increased with a decrease in temperature, while the ratio was quite stable for I. galbana and Thalassiosira pseudonana. A high $E / E_{\mathrm{k}}$ ratio indicates light saturation and an imbalance between light-harvesting and downstream photosynthetic reactions (Anning et al. 2001), while a ratio around 1 indicates optimization of light harvesting with photosynthetic metabolism as a function of the incident light. In the present study, it appears that, except for I. galbana and T. pseudonana, which exhibited a relatively stable value of $E / E_{\mathrm{k}}$ (Fig. 5), the other species were not able to acclimate their light-harvesting capacity at extreme temperatures after at least 1 wk of acclimation. Anning et al. (2001) described an increase of the ratio $E / E_{\mathrm{k}}$ in the marine diatom Chaetoceros calcitrans at low temperature, as we observed particularly for S. marinoi and L. chlorophorum and more generally for all tested species. This confirms the apparent similarity of acclimation at low temperature and high irradiance. The broad range of $E / E_{\mathrm{k}}$ responses confirms that temperature acclimation is 
species dependent, i.e. various mechanisms and strategies implicating light harvesting and the whole downstream photosynthetic metabolism are responsible for this heterogenic response (Davison 1991, Thompson 2006). For example, RUBISCO activity, particularly at high temperature, depends on chaperon proteins which maintain RUBISCO's function, and these accompanying proteins are interspecifically variable (Thompson 2006). The use of rapid light curves defined as very short light steps of different irradiances may lead to a wrong estimation of ETR $\mathrm{max}_{\max }$ and consequently of $E_{\mathrm{k}}$ (Serôdio et al. 2005). However Perkins et al. (2006) showed that for diatoms light steps with durations longer than $30 \mathrm{~s}$ were suitable. In the present study, light steps of $40 \mathrm{~s}$ were applied, and we observed that the fluorescence steady state was reached at all irradiances for all species and for all temperature treatments.

The concentrations of TEP measured in the present study (1 to $382 \mathrm{mg}$ Xeq $(\mathrm{mg} \mathrm{chl} \mathrm{a})^{-1}$ ) are within the range (1 to $3700 \mathrm{mg}$ Xeq $(\mathrm{mg} \mathrm{chl} \mathrm{a})^{-1}$ ) presented by Passow (2002a) in a review synthesizing data on 22 microalgae belonging to various phyla. In our study, the dinoflagellate Lepidodinium chlorophorum produced the most TEP (159 mg Xeq [mg chl a $]^{-1} \mathrm{~d}^{-1}$ ); this echoes the results of Passow (2002b), who measured high production of TEP per cell (1309 pg Xeq cell ${ }^{-1}$, corresponding to $70 \mathrm{mg}$ Xeq $[\mathrm{mg} \mathrm{chl} \mathrm{a}]^{-1}$; Passow 2002a) in the dinoflagellate Gonyaulax polyedra. Passow (2002a) reported low TEP production (1 to 7 Xeq $[\mathrm{mg} \mathrm{chl} \mathrm{a}]^{-1}$ ) in a non calcifying strain of Emiliania huxleyi, whereas we measured higher production (between 12 and $25 \mathrm{mg}$ Xeq $[\mathrm{mg} \mathrm{chl} \mathrm{a}]^{-1} \mathrm{~d}^{-1}$ ) in a calcified strain of the same species.

In the present study, temperature influenced TEP production in the 3 diatoms and both Isochrysis strains, but did not affect TEP production in Emiliania huxleyi and Lepidodinium chlorophorum (Fig. 6). In the case of I. galbana, this appears to contradict the result of Zlotnik \& Dubinsky (1989), who found that temperature did not affect DOC excretion. TEP formation, and carbon excretion in general, is known to be strongly influenced by nutrient status; however, in the present study, growth was not nutrient limited and was controlled only by temperature. Contrary to Wolfstein \& Stal (2002), who observed higher EPS production per chl $a$ unit at low temperature in batch culture for the diatom Cylindrotheca closterium, we observed for the tested diatoms an increase of EPS production up to an optimal temperature and then a decrease at high temperature. For the 3 diatoms, and in contrast to the other species, TEP production was significantly linearly related to photosynthetic activity (Fig. 7); this indicated that carbon excretion was not simply due to an overflow of carbon resulting from unbalanced growth, but on the contrary to a balance between production and excretion of carbon. This balance may be due to the semi-continuous culture conditions, which allow a better equilibrium between metabolic pathways than under batch culture (MacIntyre \& Cullen 2005). Underwood et al. (2004) found that 2 distinct types of EPS were produced by C. closterium depending on nutrient status: one type being produced during nutrientreplete culture (EPS type 1$)$ and the other type being produced in addition during nutrient stress $\left(\mathrm{EPS}_{\mathrm{type}}\right)$. Applying this model to our data for pelagic diatoms, it can be argued that under thermal acclimation the EPS $_{\text {type2 } 2}$ would not be formed, while EPS type1 $_{\text {produc- }}$ tion would be coupled with carbon production. In the study of Wolfstein \& Stal (2002), EPS production of $C$. closterium may have decreased at low temperature with increasing age of the culture as a result of thermal acclimation and decreasing thermal stress. Analyses of TEP and EPS composition as a function of thermal acclimation would be an interesting next step for further investigation. The cultures performed in this study were conducted under continuous illumination, which could have amplified carbohydrate metabolism and thus carbon excretion. The use of a light/dark cycle in future studies would allow quantification of this potential effect.

The rate of photosynthesis estimated by PAM fluorometry and oxygen evolution or carbon fixation have been compared in several phytoplankton species (Flameling \& Kromkamp 1998, Morris \& Kromkamp 2003, Lefebvre et al. 2007), which allows estimation of the number of mol of $\mathrm{C}$ fixed per mol of electrons. Morris \& Kromkamp (2003) found a value of $0.114 \mathrm{~mol}$ $\mathrm{C}$ (mol electron) ${ }^{-1}$. In order to estimate carbon fixation in our study, we used this factor to convert the ETR $\left(\mathrm{mmol} \mathrm{e}^{-}[\mathrm{mg} \mathrm{chl} \mathrm{a}]^{-1} \mathrm{~h}^{-1}\right.$ ) at growth irradiance (i.e. photosynthetic activity) into carbon expressed in $\mathrm{mg} \mathrm{C}$ $(\mathrm{mg} \mathrm{chl} \mathrm{a})^{-1} \mathrm{~h}^{-1}$. TEP concentrations (Xeq [mg chl a $]^{-1}$ ) were also converted to carbon, in light of the work of Engel \& Passow (2001), who determined ratios between TEP carbon ( $\mu \mathrm{g} C$ ) and TEP ( $\mu$ g Xeq) in several species. A ratio between TEP carbon $\left(\mathrm{mg} \mathrm{C} \mathrm{chl} \mathrm{a}^{-1}\right)$ and TEP (Xeq [mg chl a $]^{-1}$ ) of 0.70 was applied. These conversions allow estimation of the percentage of photosynthetic carbon which was excreted in the form of TEPs. For the 3 diatoms, the linear relationship between calculated carbon production and TEP production was obviously similar to the one between ETR at growth irradiance and TEP (Fig. 7), but the absolute values of slopes changed. The slope values were, respectively, $0.067,0.20$ and 0.30 for Thalassiosira pseudonana, Skeletonema marinoi and Pseudonitzschia fraudulenta, which signifies that, respectively, $6.7,20$ and $30 \%$ of the photosynthetic carbon production was excreted as TEP. Estimations reported 
in the literature for benthic diatoms, which are known to produce large amounts of EPS, range from 30 to $73 \%$ of photosynthate being excreted, whereas for pelagic phytoplankton estimations range from 1.5 to $22 \%$ (Goto et al. 1999, Smith \& Underwood 2000). Because no relationships were found between photosynthetic production and TEP production for the other species, this percentage was estimated at $T_{\text {opt(ETR) }}$ at growth irradiance: $17.3 \%$ was calculated for Emiliania huxleyi, 6.8\% for Isochrysis galbana, 15.9\% for I. aff. galbana and $70.8 \%$ for Lepidodinium chlorophorum.

Even though dinoflagellates are known to excrete large amounts of carbon (Passow 2002b) and the presence of large amounts of TEPs in the Lepidodinium chlorophorum cultures was confirmed by light microscopic observations, the percentage of carbon production estimated to be excreted in L. chlorophorum seems abnormally high. There are a number of potential explanations for this: (1) heterotrophy, frequently described in dinoflagellates, would affect this estimation, but no organic material except that excreted by the microalgae was present in the medium; (2) the presence of bacteria, which are known to produce EPS and TEPs, would be another potential source of bias, but high levels of contamination would have been detected by microscopic observations; (3) dinoflagellates tend to be relatively fragile and a stress reaction during sampling may have influenced measurements. TEP concentration is often high in blooms dominated by dinoflagellates in the natural environment (Passow 2002a). Irrespective of the accuracy of this estimation, L. chlorophorum is known to produce large slimy blooms which can create anoxic conditions (Sournia et al. 1992), and ecdysis and the formation of mucocysts have been reported for this species (Elbrächter \& Schnepf 1996). The high level of carbon excretion would facilitate aggregation and bloom sedimentation and hence contribute to the dramatic consequences of such blooms. According to our data, an increase in temperature would not amplify this potential phenomenon of aggregation (and other effects of TEPs) for L. chlorophorum and Emiliania huxleyi, but would do so for the 2 Isochrysis strains and diatoms.

\section{CONCLUSIONS}

In the present study, the growth and $\mathrm{ETR}_{\max }$ of 8 common microalgal species of interest in ecological and/or aquacultural terms were characterised. The photosynthetic acclimation that we observed was roughly in accordance with literature reports, but the species-specific trends of $E / E_{\mathrm{k}}$ merit further study. The linear relationship observed in diatoms between TEP production and photosynthesis during balanced nutri- ent-replete growth provides a new way to consider carbon excretion, which has most frequently been described to be a consequence of stress. Underwood et al. (2004), focusing on EPS composition and metabolic pathways of EPS production as a function of environmental conditions, provide a basis for future work aimed at acquiring a better knowledge of the dynamics of excretion of organic compounds which play an important role in global carbon fluxes. In this context, our study demonstrates the differential interactions between photosynthesis and TEP production between species, highlighting the potential of inter-specific comparisons for developing our understanding of the metabolic mechanisms involved in TEP production. Because TEP formation influences aggregation mechanisms, grazing and virus attack, processes which are involved in the fate of phytoplankton blooms, accurate prediction of carbon excretion by phytoplankton is important for improving the simulation of bloom dynamics.

Acknowledgements. This work was supported by the Successphyto program (Agence de l'eau Seine-Normandie, Conseil Général du Calvados, Conseil Régional BasseNormandie) and the GDR-IFREMER microalgues program. We are grateful to our students Vincent Bian and Karen Lebret for technical assistance.

\section{LITERATURE CITED}

Anning T, Harris G, Geider RJ (2001) Thermal acclimation in the marine diatom Chaetoceros calcitrans (Bacillariophyceae). Eur J Phycol 36:233-241

Arruda Fatibello SHS, Augusto Henriques Vieira A, FatibelloFilho O (2004) A rapid spectrophotometric method for the determination of transparent exopolymer particles (TEP) in freshwater. Talanta 62:81-85

Berges JA, Varela DE, Harrison PJ (2002) Effects of temperature on growth rate, cell composition and nitrogen metabolism in the marine diatom Thalassiosira pseudonana (Bacillariophyceae). Mar Ecol Prog Ser 225:139-146

Blanchard GF, Guarini JM, Richard P, Gros P, Mornet F (1996) Quantifying the short-term temperature effect on lightsaturated photosynthesis of intertidal microphytobenthos. Mar Ecol Prog Ser 134:309-313

Brussaard CPD, Kuipers B, Veldhuis MJW (2005) A mesocosm study of Phaeocystis globosa population dynamics. 1. Regulatory role of viruses in bloom. Harmful Algae 4:859-874

> Davison IR (1991) Environmental effects on algal photosynthesis: temperature. J Phycol 27:2-8

Dubinsky Z, Falkowski PG, Wyman K (1986) Light harvesting and utilisation by phytoplankton. Plant Cell Physiol 27: $1335-1349$

Elbrächter M, Schnepf E (1996) Gymnodinium chlorophorum, a new green, bloom-forming dinoflagellate (Gymnodiniales, Dinophyceae) with a vestigial prasinophyte endosymbiont. Phycologia 35:318-393

El-Sabaawi R, Harrison PJ (2006) Interactive effects of irradiance and temperature on the photosynthetic physiology of the pennate diatom Pseudo-nitzschia granii (Bacillariophyceae) from the Northeast Subarctic Pacific. J Phycol 42:778-785 
Engel A, Passow U (2001) Carbon and nitrogen content of transparent exopolymer particles (TEP) in relation to their Alcian Blue adsorption. Mar Ecol Prog Ser 219:1-10

Flameling IA, Kromkamp J (1998) Light dependence of quantum yields for PSII charge separation and oxygen evolution in eucaryotic algae. Limnol Oceanogr 43: 284-287

Genty B, Briantais J, Baker NR (1989) The relationship between the quantum yield of photosynthetic electron transport and of quenching chlorophyll fluorescence. Biochim Biophys Acta 990:87-92

Gilbert M, Wilhelm C, Richter M (2000) Bio-optical modelling of oxygen evolution using in vivo fluorescence: comparison of measured and calculated photosynthesis/irradiance (P-I) curves in four representative phytoplankton species. J Plant Physiol 157:307-314

Goto N, Kawamura T, Mitamura O, Terai H (1999) Importance of extracellular organic carbon production in the total primary production by tidal-flat diatoms in comparison to phytoplankton. Mar Ecol Prog Ser 190:289-295

Lefebvre S, Mouget JL, Loret P, Rosa P, Tremblin G (2007) Comparison between fluorimetry and oximetry techniques to measure photosynthesis in the diatom Skeletonema costatum cultivated under simulated seasonal conditions. J Photochem Photobiol 86:131-139

Longhi ML, Schloss IR, Wiencke C (2003) Effect of irradiance and temperature on photosynthesis and growth of two Antarctic benthic diatoms, Gyrosigma subsalinum and Odontella litigiosa. Bot Mar 46:276-284

MacIntyre HL, Cullen JJ (2005) Using cultures to investigate the physiological ecology of microalgae. In: Andersen RA (ed) Algal culturing techniques. Elsevier Academic Press, Amsterdam, p 287-326

Morris EP, Kromkamp JC (2003) Influence of temperature on the relationship between oxygen- and fluorescence-based estimates of photosynthetic parameters in a marine benthic diatom (Cylindrotheca closterium). Eur J Phycol 38:133-142

Passow U (2002a) Transparent exopolymer particles (TEP) in aquatic environments. Prog Oceanogr 55:287-333

Passow U (2002b) Production of transparent exopolymer particles (TEP) by phyto- and bacterioplankton. Mar Ecol Prog Ser 236:1-12

Passow U, Alldredge A (1995) A dye-binding assay for the spectrophotometric measurement of transparent exopolymer particles (TEP). Limnol Oceanogr 40:1326-1335

> Perkins RG, Mouget JL, Lefebvre S, Lavaud J (2006) Light response curve methodology and possible implications in the application of chlorophyll fluorescence to benthic diatoms. Mar Biol 149:703-712

Prieto L, Sommer F, Stibor HN, Koeve W (2001) Effects of planktonic copepods on transparent exopolymeric particles (TEP) abundance and size spectra. J Plankton Res 23:515-525

Ralph PJ, Gademann R (2005) Rapid light curves: a powerful tool to assess photosynthetic activity. Aquat Bot 82: 222-237

Ratkowski DA (1983) Non linear regression modeling. A unified practical approach. Marcal Dekker, New York
Sakshaug E, Bricaud A, Dandonneau Y, Falkowski PG and others (1997) Parameters of photosynthesis: definitions, theory and interpretation of results. J Plankton Res 19: 1637-1670

Sarno D, Kooistra WHDF, Medlin LK, Percopo I, Zingone A (2005) Diversity of the genus Skeletonema (Bacillariophyceae). II. An assessment of the taxonomy of S. costatum-like species with description of four new species. J Phycol 41:151-176

Schreiber U, Schliwa U, Bilger W (1986) Continuous recording of photochemical and non-photochemical chlorophyll fluorescence quenching with a new type of modulation fluorometer. Photosynth Res 10:51-62

- Serôdio J, Viera S, Cruz S, Barroso F (2005) Short-term variability in the photosynthetic activity of microphytobenthos as detected by measuring light curves using variable fluorescence. Mar Biol 146:903-914

Shibata K, Bonson AA, Calvin M (1954) The absorption spectra of suspensions of living micro-organisms. Biochim Biophys Acta 15:461-470

Smith DJ, Underwood GJC (2000) The production of extracellular carbohydrates by estuarine benthic diatoms: the effects of growth phase and light and dark treatment. J Phycol 36:321-333

Sournia A, Belin C, Billard C, Catherine M and others (1992) The repetitive and expanding occurrence of a green, bloom-forming dinoflagellate (Dinophyceae) on the coasts of France. Cryptogam Algol 13:1-13

> Staats N, Stal LJ, Mur LR (2000) Exopolysaccharide production by the epipelic diatom Cylindrotheca fusiformis: effects of nutrient conditions. J Exp Mar Biol Ecol 249:13-27

Straskraba M, Gnauck A (1985) Freshwater ecosystems: modelling and simulation. Elsevier, Amsterdam

Suzuki Y, Takahashi M (1995) Growth responses of several diatom species isolated from various environments to temperature. J Phycol 31:880-888

Thompson P (2006) Effects of temperature and irradiance on marine microalgal growth and physiology. In: Subba Rao DV (ed) Algal cultures, analogues of blooms and applications. Science Publishers, Enfield, NH, p 571-638

Thornton DCO (2002) Diatom aggregation in the sea: mechanisms and ecological implications. Eur J Phycol 37: $149-161$

Underwood GJC, Boulcott M, Raines CA, Waldron K (2004) Environmental effects on exoplymer production by marine benthic diatoms: dynamics, changes in composition, and pathways of production. J Phycol 40:293-304

- Webb WL, Newton M, Starr D (1974) Carbon dioxide exchange of Alnus rubra. Oecologia 17:281-291

> Wilhelm C, Buchel C, Fisahn J, Goss R and others (2006) The regulation of carbon and nutrient assimilation in diatoms is significantly different from green algae. Protist 157: 91-124

> Wolfstein K, Stal LJ (2002) Production of extracellular polymeric substances (EPS) by benthic diatoms: effect of irradiance and temperature. Mar Ecol Prog Ser 236:13-22

Zlotnik I, Dubinsky Z (1989) The effect of light and temperature on DOC excretion by phytoplankton. Limnol Oceanogr 34:831-839

Submitted: September 10, 2007; Accepted: February 14, 2008 Proofs received from author(s): April 1, 2008
Editorial responsibility: Hugh MacIntyre,

Dauphin Island, Alabama, USA 